\title{
Evaluation of ophthalmic manifestations according to insulin resistance, lipid and pubertal status in obese and healthy children
}

\author{
Bengi Ece Kurtul ${ }^{1}$, Emrah Utku Kabatas ${ }^{1}$, Pinar Altiaylik Ozer² FEBO, Ayla Akca Caglar ${ }^{2}$, Erdal Kurnaz ${ }^{4}$, Elvan Bayramoglu ${ }^{4}$ and Zehra \\ Aycan $^{4}$ \\ ${ }^{1}$ Department of Ophthalmology, Dr. Sami Ulus Maternity and Children's Health and Diseases Training and Research Hospital, Ankara, Turkey. \\ ${ }^{2}$ Department of Ophthalmology, Ufuk University School of Medicine, Ankara, Turkey. \\ ${ }^{3}$ Department of Pediatrics, Dr. Sami Ulus Maternity and Children's Health and Diseases Training and Research Hospital, Ankara, Turkey. \\ ${ }^{4}$ Department of Pediatric Endocrinology, Dr. Sami Ulus Maternity and Children's Health and Diseases Training and Research Hospital, Ankara, Turkey. \\ ${ }^{5}$ Department of Pediatric Endocrinology, Dr. Sami Ulus Maternity and Children's Health and Diseases Training and Research Hospital, Ankara, Turkey.
}

\begin{abstract}
Purpose: We aimed to evaluate the ophthalmic manifestations in terms of insulin resistance (IR), lipid and pubertal status in obese and healthy children.

Methods: Subjects (aged from 5 to17 years) were divided into 2 groups according to their body mass index (BMI) percentiles as obese and non-obese and 4 subgroups according to absence or presence of insulin resistance, hyperlipidemia and pubertal status. Sixty obese children (BMI $>95$ th percentile), 58 healthy control subjects with the same age range (BMI <85th percentile) were admitted to this prospective study. Demographic features and laboratory measurements of subjects were recorded. Ophthalmological examination, including ocular surface parameters, intraocular pressure, central corneal thickness (CCT), and biometric measurements were assed among subgroups.
\end{abstract}

Results: The subjects in obese group were significantly more hypertensive than control group [13 patients (21.7\%), and 1 patient (1.7\%) respectively, ( $\mathrm{p}=0.001)$ ]. Incidence of hyperinsulinism and the homeostasis model assessment for IR (HOMA-IR) levels and of obese children were significantly higher than control group $(\mathrm{p}=0.003$, and $\mathrm{p}=0.034$, respectively). The rate of hypertensive retinopathy was significantly higher in obesity $(+)$ hyperlipidemia $(+)$ subgroup $(\mathrm{p}=0.002)$. The mean CCT values were significantly lower in obesity $(+)$ IR $(+)$ subgroup $(\mathrm{p}=0.023)$. Schirmer test scores were significantly lower in obesity $(-)$ subgroups regardless of IR, lipid and pubertal status.

Conclusions: Our findings suggest that decreased CCT levels may be related to presence of IR in obese children. The coexistence of hypertensive retinopathy with hyperlipidemia may occur in childhood obesity.

\section{Introduction}

During the last 20 years obesity has become a major public health problem in advanced and developing countries [1,2]. Obesity is one of the most pressing challenges that humanity faces today [3]. Insulin resistance (IR) is one of the most concerning complications of childhood obesity (CO) [4]. Both environmental and genetic factors are involved in the pathogenesis of IR. IR is the state of reduced tissue sensitivity to insulin [4]. IR is more frequent in children with very high BMI [5]. IR is considered to be a chronic low-grade inflammation $[6,7]$. We hypothesized that dry eye, as an inflammatory disease, may be correlated with obesity in these children based on the role of this inflammation leading to overweight and obesity.

Hyperlipidemia is another risk factor related to CO [4]. It is estimated that approximately $42 \%$ of obese children have lipid abnormalities [4]. The most common lipid abnormality pattern consists of elevated triglycerides, decreased high-density lipoprotein cholesterol and normal to mildly elevated low-density lipoprotein cholesterol [4]. Ophthalmological complications of hypertriglyceridaemia include eruptive, and other forms of xanthomata including xanthelasmata, corneal arcus, lipaemia retinalis, decrease in retinal blood flow, and lipid emboli affecting vision [8].
Puberty leads to the maturation of secondary sex characteristics, height increase, and attainment of reproductive capacity. $\mathrm{CO}$ also contributes to early onset of puberty [9]. Pubertal growth spurt may lead to the changes in ophthalmic examination in both genders. We are interested in the influence of pubertal status on ophthalmic findings in obese children.

Although obesity is becoming a major cause of morbidity in children with effects later on in adult life, as far as we know, there is no data about comparison of ocular surface parameters, and limited data on intraocular pressure, central corneal thickness, and biometric measurements in terms of IR, lipid and pubertal status between obese and healthy children. Therefore, we aimed to investigate this issue.

Correspondence to: Bengi Ece Kurtul, Department of Ophthalmology, Dr. Sami Ulus Maternity and Children's Health and Diseases Training and Research Hospital, Ankara, Turkey, E-mail: becekurtul@yahoo.com

Key words: childhood obesity, hyperlipidemia, insulin resistance, ophthalmic manifestations, puberty

Received: October 05, 2017; Accepted: October 27, 2017; Published: October 30, 2017 


\section{Materials and methods}

This study was undertaken as a prospective analysis between January 2016 and April 2016, in Training and Research Hospital. A total of 118 patients who were referred by our pediatric endocrinology department to our ophthalmology outpatient clinic, were enrolled in this study. The inclusion criteria for the study groups were primary obesity (body mass index $(\mathrm{BMI})>95^{\text {th }}$ percentile for sex and age) and healthy children within the same age range with normal BMI $\left(<85^{\text {th }}\right.$ percentile). Study subjects also were divided into 4 subgroups according to absence or presence of insulin resistance, hyperlipidemia and pubertal status. Exclusion criteria included over-weight children $\left(85^{\text {th }}\right.$ $95^{\text {th }}$ percentiles for BMI), previous glaucoma, orbital masses, severe myopia ( $>6 \mathrm{D})$, diseases of the cornea, the presence of cardiovascular, renal, neurological, thyroid, mental, metabolic disorders and genetic syndromes.

Each subject underwent full ophthalmologic examination including best-corrected visual acuity, biomicroscopic anterior segment and fundus examination, and IOP measurement by noncontact tonometer (Reichert 7 CR Corneal Response Technology, USA). Three consecutive IOP measurements were taken for each eye and the mean value was recorded. Visual acuity test results, detection of significant refractive errors following cycloplegia, and ocular alignment findings based on cover-uncover, alternate cover, and Hirschberg testing were recorded for each subject. Snellen or HOTV testing was used to determine visual acuity. Cycloplegic retinoscopy and fundus examination following dilation of the pupils with cyclopentolate $1 \%$ were also performed. The refractive status of each subject was assessed using a hand-held automated refractometer (SureSightTM autorefractor, Welch Allyn, Skaneateles Falls, NY, USA). The ultrasonic pachymeter and A-mode biometry probe (Nidek US-4000 Echoscan, Japan) were used to determine CCT and axial length, respectively. After administering topical proparacaine hydrochloride $0.5 \%$ (Alcaine ophthalmic solution, Alcon, Turkey), measurements were taken with the tip of the probe targeting the center of the pupil and perpendicular to the cornea while the subject was looking at a fixed target. The probe was sterilized with alcohol after each subject was examined. At least 5 consecutive measurements were obtained for each eye and the mean value was recorded. Tear break up time (TBUT) and Schirmer 1 test with topical anesthesia were performed to all patients 30 minutes after full ophthalmologic examination. The TBUT was measured after fluorescein staining. Subjects were instructed to blink, and the tear film was examined using the cobalt blue filter of a slit-lamp biomicroscope. The time interval in seconds between the instilment of fluorescein and the appearance of the first randomly distributed dry spot was enrolled as the TBUT. This method was repeated three times for each eye, and the average of the results was registered as the mean TBUT. TBUT of less than 10 seconds was determined as abnormal. The Schirmer 1 test was applied by placing a standardized strip of filter paper in the $1 / 3$ lateral tarsal conjunctiva away from the cornea. Outcomes were expressed in millimeters after 5 minutes of wetting [10].

Prevalence of obesity was defined using BMI percentiles for age and sex. Obesity in children was defined when a BMI was greater than the $95^{\text {th }}$ percentile for age and sex according to the reference values for the Turkish pediatric population [11]. BMI was calculated based on the formula: $\mathrm{BMI}=\left[\right.$ weight $/$ height $\left.^{2}\left(\mathrm{~kg} / \mathrm{m}^{2}\right)\right][4]$.

Pubertal stage was based on Tanner's classification and divided into prepubertal (Tanner stage 1) and pubertal (Tanner stage 2-5) subjects including stage 2 thelarche in females, $>4 \mathrm{ml}$ testis volume in males [12].
Laboratory findings were recorded from the patients' data. All children had undergone a 12-hour fast prior to blood sampling. Blood lipid and fasting glucose levels were evaluated by Beckman Coulter DXC 800/USA biochemical analyzer. Hyperlipidemia was diagnosed as $>110 \mathrm{mg} / \mathrm{dL}$ for low-density lipoprotein cholesterol, $<40 \mathrm{mg} / \mathrm{dL}$ for high-density lipoprotein cholesterol, $>170 \mathrm{mg} / \mathrm{dL}$ for total cholesterol and $>150 \mathrm{mg} / \mathrm{dL}$ for triglyceride levels [13]. Insulin levels were determined by ADVIA Centaur XP Immunoassay System (Siemens, Germany) analyzer. Hyperinsulinism was diagnosed as fasting insulin levels $>15$ for pubertal stage $1,>20$ for pubertal stage 2-3 and $>30$ for pubertal stage 5 . In clinical practice, the homeostasis model assessment-insulin resistance (HOMA-IR) index is used to diagnose IR [4]. HOMA-IR index was calculated based on the formula: HOMA-IR= insulin $(\mathrm{mU} / \mathrm{L}) \times$ glucose $(\mathrm{mmol} / \mathrm{L}) / 22.5$, taking 2.6 for prepubertal male and 2.2 for prepubertal female, and 5.2 for pubertal male and 3.8 for pubertal female as the cutoff value for the diagnosis of IR [14].

This study was carried out with the Institutional Review Board/ Ethics Committee approval. The research adhered to the tenets of the Declaration of Helsinki. Informed consent was obtained from all parents after explaining the nature and purpose of the study.

\section{Statistical analysis}

All analyses were performed using SPSS for Windows 18.0 (version 18.0, SPSS, Chicago, IL, USA). Continuous variables are presented as mean \pm standard deviation (SD). Continuous variables were compared using Student's unpaired t tests or Mann-Whitney nonparametric $\mathrm{U}$ tests. Categorical variables were compared using chi-square statistics. Comparison of parametric values among groups was performed by One- Way ANOVA. A two-tailed $\mathrm{p}$ value $<0.05$ was considered as significant.

\section{Results}

The subjects in obese group were significantly more hypertensive than control group $(\mathrm{p}=0.001)$. Incidence of hyperinsulinism and HOMA-IR levels and of obese children were significantly higher than control group ( $\mathrm{p}=0.003$, and $\mathrm{p}=0.034$, respectively). The baseline demographic features and laboratory measurements of study subjects were shown in (Table 1). Spherical values were between $-1.75 \mathrm{D}$ and $+3.00 \mathrm{D}$ in obese group, $-3.50 \mathrm{D}$ and $+2.00 \mathrm{D}$ in control group. All astigmatism values were recorded in plus cylinder; cylindrical values were between $+0.50 \mathrm{D}$ and $+2.75 \mathrm{D}$ in both groups. Comparison of ophthalmic pathologies of study subjects according to insulin resistance, lipid and pubertal status were shown in (Table 2, 3, 4). The mean central corneal thickness values were significantly lower in obesity + and insulin resistance + subgroup $(\mathrm{p}=0.023)$ (Table 2). Schirmer test scores were significantly lower in obesity - subgroups regardless of insulin resistance, lipid and pubertal status (Table 2, 3, 4). The rate of hypertensive retinopathy was significantly higher in obesity + hyperlipidemia + subgroup $(\mathrm{p}=0.002)$ (Table 3$)$.

\section{Discussion}

To the best of our knowledge, this is the first study that demonstrates the comparison of ocular surface clinical parameters in terms of insulin resistance, lipid and pubertal status between obese and normal weight healthy children.

The frequency of IR occurrence is increasing dramatically in developed countries. IR occurs physiologically during puberty, but it is also a pathological condition predisposing child to develop abnormal glucose tolerance, diabetes, hypertension and polycystic ovary 
Table 1. Baseline demographic features and laboratory measurements of study subjects.

\begin{tabular}{|c|c|c|c|}
\hline Variable & $\begin{array}{c}\text { Obese } \\
(\mathrm{n}=60)\end{array}$ & $\begin{array}{l}\text { Non-Obese } \\
(\mathrm{n}=58)\end{array}$ & $\mathrm{p}$ \\
\hline Age & $11.0 \pm 3.0$ & $11.8 \pm 3.0$ & 0.146 \\
\hline Gender (boy) & $33(55 \%)$ & $33(55 \%)$ & $33(55 \%)$ \\
\hline Body Mass Index & $28.5 \pm 5.4$ & $22.3 \pm 3.9$ & $<0.001$ \\
\hline Hypertension & $13(21.7 \%)$ & $1(1.7 \%)$ & 0.001 \\
\hline Total cholesterol & $166 \pm 33$ & $163 \pm 26$ & 0.595 \\
\hline High density lipoprotein & $48 \pm 11$ & $52 \pm 13$ & 0.094 \\
\hline Low density lipoprotein & $102 \pm 26$ & $94 \pm 23$ & 0.076 \\
\hline Trigliceride & $103 \pm 44$ & $101 \pm 42$ & 0.802 \\
\hline Glucose & $91 \pm 8.0$ & $91 \pm 7.0$ & 0.681 \\
\hline Insulin & $18.3 \pm 9.8$ & $14.5 \pm 7.1$ & 0.019 \\
\hline Hyperinsulinism & $29(48.3 \%)$ & $13(22.4 \%)$ & 0.003 \\
\hline Insulin Resistance & $35(58.3 \%)$ & $24(41.4 \%)$ & 0.066 \\
\hline HOMA-IR & $4.13 \pm 2.5$ & $3.27 \pm 1.6$ & 0.034 \\
\hline Prepuberty (Tanner Stage 1) & $23(38.3 \%)$ & $15(25.9 \%)$ & 0.321 \\
\hline Puberty (Tanner Stage 2-5) & $37(61.7 \%)$ & $43(74.1 \%)$ & 0.321 \\
\hline Precoccious puberty & $2(3.3 \%)$ & $0(0 \%)$ & 0.161 \\
\hline
\end{tabular}

Table 2. Ophthalmic pathologies and clinical measurements of study subgroups according to insulin resistance status.

\begin{tabular}{|c|c|c|c|c|c|}
\hline Ophthalmic findings & $\begin{array}{c}\text { Obesity - } \\
\text { IR - } \\
n=34\end{array}$ & $\begin{array}{c}\text { Obesity - } \\
\text { IR + } \\
n=24\end{array}$ & $\begin{array}{c}\text { Obesity }+ \\
\text { IR - } \\
n=25\end{array}$ & $\begin{array}{c}\text { Obesity+ } \\
\text { IR + } \\
n=35\end{array}$ & $\mathrm{p}$ \\
\hline Strabismus & $0(0 \%)$ & $0(0 \%)$ & $1(4 \%)$ & $0(0 \%)$ & 0.29 \\
\hline Lens opacities & $0(0 \%)$ & $1(4 \%)$ & $0(0 \%)$ & $1(2.9 \%)$ & 0.556 \\
\hline Refractive errors & $6(21.2 \%)$ & $6(24 \%)$ & $10(40 \%)$ & $5(24.3 \%)$ & 0.139 \\
\hline Ambliyopia & $3(9.1 \%)$ & $1(4 \%)$ & $3(12 \%)$ & $2(5.7 \%)$ & 0.699 \\
\hline Central Corneal Thickness & $555 \pm 31$ & $544 \pm 42$ & $550 \pm 31$ & $530 \pm 27$ & 0.023 \\
\hline Intraocular Pressure & $15.4 \pm 2.3$ & $15.8 \pm 2.8$ & $15.8 \pm 2.8$ & $14.7 \pm 2.4$ & 0.327 \\
\hline Schirmer test (mm) & $7.7 \pm 4.6$ & $12.3 \pm 7.4$ & $15.5 \pm 8.8$ & $15.5 \pm 8.8$ & $<0.001$ \\
\hline Break-up time (sec) & $10.6 \pm 1.3$ & $10.6 \pm 1.3$ & $10.0 \pm 2.9$ & $9.8 \pm 2.3$ & 0.551 \\
\hline Axial length (mm) & $22.8 \pm 1.2$ & $23.2 \pm 0.8$ & $23.3 \pm 0.7$ & $22.8 \pm 1.1$ & 0.262 \\
\hline Lens thickness (mm) & $3.6 \pm 0.3$ & $3.4 \pm 0.2$ & $3.5 \pm 0.2$ & $3.5 \pm 0.2$ & 0.17 \\
\hline Anterior chamber depth $(\mathrm{mm})$ & $3.6 \pm 0.3$ & $3.6 \pm 0.2$ & $3.5 \pm 0.2$ & $3.5 \pm 0.2$ & 0.097 \\
\hline Vitreous chamber depth (mm) & $15.6 \pm 1.1$ & $16.0 \pm 0.8$ & $15.5 \pm 2.8$ & $15.9 \pm 1.9$ & 0.573 \\
\hline Hypertensive retinopathy & $0(0 \%)$ & $0(0 \%)$ & $1(4 \%)$ & $1(2.9 \%)$ & 0.556 \\
\hline \multicolumn{6}{|l|}{ IR: Insulin resistance } \\
\hline
\end{tabular}

Table 3. Ophthalmic pathologies and clinical measurements of study subgroups according to lipid status

\begin{tabular}{|c|c|c|c|c|c|}
\hline Ophthalmic findings & $\begin{array}{c}\text { Obesity - Hyperlipidemia } \\
-\mathrm{n}=42\end{array}$ & $\begin{array}{c}\text { Obesity - Hyperlipidemia } \\
+\mathrm{n}=16\end{array}$ & $\begin{array}{c}\text { Obesity }+ \text { Hyperlipidemia } \\
-\mathrm{n}=41\end{array}$ & $\begin{array}{c}\text { Obesity }+ \text { Hyperlipidemia } \\
+\mathrm{n}=19\end{array}$ & $\mathrm{p}$ \\
\hline Strabismus & $0(0 \%)$ & $0(0 \%)$ & $1(2.6 \%)$ & $0(0 \%)$ & 0.595 \\
\hline Lens opacities & $0(0 \%)$ & $1(6.3 \%)$ & $1(2.4 \%)$ & $0(0 \%)$ & 0.365 \\
\hline Refractive errors & $9(21.4 \%)$ & $4(25 \%)$ & $12(29.3 \%)$ & $3(15.8 \%)$ & 0.684 \\
\hline Ambliyopia & $3(7.1 \%)$ & $1(6.3 \%)$ & $5(12.2 \%)$ & $0(0 \%)$ & 0.417 \\
\hline Central Corneal Thickness & $533 \pm 37$ & $545 \pm 36$ & $535 \pm 24$ & $544 \pm 40$ & 0.153 \\
\hline Intraocular Pressure & $15.7 \pm 2.6$ & $15.0 \pm 2.3$ & $14.8 \pm 1.9$ & $15.2 \pm 2.6$ & 0.399 \\
\hline Schirmer test (mm) & $9.4 \pm 6.1$ & $10.4 \pm 7.3$ & $16.3 \pm 8.9$ & $15.4 \pm 6.7$ & $<0.001$ \\
\hline Break-up time (sec) & $10.6 \pm 1.7$ & $9.9 \pm 1.6$ & $9.6 \pm 2.7$ & $10.3 \pm 2.3$ & 0.304 \\
\hline Axial length (mm) & $23.0 \pm 1.0$ & $22.7 \pm 1.2$ & $23.2 \pm 0.8$ & $22.5 \pm 1.3$ & 0.237 \\
\hline Lens thickness (mm) & $3.5 \pm 0.2$ & $3.5 \pm 0.3$ & $3.5 \pm 0.1$ & $3.5 \pm 0.3$ & 0.962 \\
\hline Anterior chamber depth (mm) & $3.6 \pm 0.2$ & $3.6 \pm 0.3$ & $3.5 \pm 0.2$ & $3.4 \pm 0.3$ & 0.133 \\
\hline Vitreous chamber depth (mm) & $15.8 \pm 1.1$ & $15.6 \pm 0.9$ & $15.7 \pm 2.2$ & $15.8 \pm 0.8$ & 0.953 \\
\hline Hypertensive retinopathy & $0(0 \%)$ & $0(0 \%)$ & $1(2.4)$ & $1(5.3 \%)$ & 0.002 \\
\hline
\end{tabular}

syndrome among girls [1]. In our study incidence of IR between groups was not significantly different. But HOMA-IR levels and incidence of hyperinsulinsm were significantly higher in obese children. CO and IR are also characterized by impaired immunity and a low-grade inflammation status depending on the multicellular release of cytokines, adipokines, and reactive oxygen species [1, 6-8, 15-17]. We thought that dry eye may be correlated with obesity in these children based on the role of this inflammation leading to overweight and obesity. However, unexpectedly, we have found significantly lower scores in control group. It may be because of the small size of the study groups. 
Table 4. Ophthalmic pathologies and clinical measurements of study subgroups according to pubertal status

\begin{tabular}{|c|c|c|c|c|c|}
\hline Ophthalmic findings & Obesity - Puberty $-\mathrm{n}=15$ & Obesity - Puberty $+n=43$ & Obesity + Puberty $-n=23$ & Obesity + Puberty $+n=37$ & $\mathrm{p}$ \\
\hline Strabismus & $0(0 \%)$ & $0(0 \%)$ & $1(3.2 \%)$ & $0(0 \%)$ & 0.419 \\
\hline Lens opacities & $1(6.3 \%)$ & $0(0 \%)$ & $0(0 \%)$ & $1(3.4 \%)$ & 0.286 \\
\hline Refractive errors & $3(19.7 \%)$ & $10(23.8 \%)$ & $6(19.4 \%)$ & $9(31 \%)$ & 0.705 \\
\hline Ambliyopia & $0(0 \%)$ & $4(9.5 \%)$ & $3(9.7 \%)$ & $2(6.9 \%)$ & 0.628 \\
\hline Central Corneal Thickness & $551+42$ & $550+34$ & $539+29$ & $535+30$ & 0.259 \\
\hline Intraocular Pressure & $15.35+3.0$ & $15.6+2.3$ & $15.0+.2 .2$ & $14.8+2.0$ & 0.55 \\
\hline Schirmer test (mm) & $9.5+7.2$ & $9.8+6.1$ & $13.3+7.7$ & $19.3+7.1$ & $<0.001$ \\
\hline Break-up time (sec) & $9.8+2.2$ & $10.6+1.4$ & $9.4+3.1$ & $10.4+1.7$ & 0.123 \\
\hline Axial length (mm) & $22.5+1.0$ & $23.1+1.1$ & $22.8+1.1$ & $23.2+0.9$ & 0.216 \\
\hline Lens thickness (mm) & $3.4+0.1$ & $3.6+0.3$ & $3.6+0.2$ & $3.4+0.1$ & 0.126 \\
\hline Anterior chamber depth (mm) & $3.5+0.2$ & $3.6+0.3$ & $3.5+0.2$ & $3.4+0.2$ & 0.094 \\
\hline Vitreous chamber depth (mm) & $15.5+1.1$ & $15.9+0.9$ & $15.3+2.4$ & $16.2+0.9$ & 0.235 \\
\hline Hypertensive retinopathy & $0(0 \%)$ & $0(0 \%)$ & $1(3.2 \%)$ & $1(3.4 \%)$ & 0.578 \\
\hline
\end{tabular}

Some epidemiological studies have described an association between obesity and IOP in adults $[18,19]$. Some authors argue that obesity increases IOP due to an excessive intraorbital adipose tissue deposit, leading to a rise in blood viscosity and episcleral venous pressure, and a consequent decrease in the facility of aqueous outflow [5]. For other authors, obesity only increases IOP when it is associated with IR [5]. The autonomic dysfunction and the osmotic gradient induced by hyperglycemia with a consequent fluid shift into the intraocular space have been proposed to explain the association between IOP and IR. A recent review concluded that there is an association between higher BMI and higher IOP in adults [2]. Akinci et al found that obesity was an independent risk factor for increased IOP [20]. In contrast to these results, Allb LL et al do not show a correlation between body mass index and IOP in children [5]. In the study of Koçak N, there were no significant differences in IOP measurements, central corneal thicknesses, cup/disc ratios and visual field parameters between obese and normal children [21]. In our study the difference among subgroups were not significantly different in terms of IOP. However, CCT values were significantly lower in obesity + and insulin resistance + subgroup. CCT could be affected with the hormonal variations of insulin.

There is no evidence that IOP influences retinal vascular caliber in healthy young children [22]. However, increasing BMI is associated with increasing retinal venular caliber over time in children [6]. In adolescents, greater body fat deposition is related to narrower retinal arterioles and wider retinal venules [23]. Progressive retinal venular widening could be a manifestation of an adverse microvascular effect of obesity early in life [6]. Young adolescents with elevated blood pressure and obesity have changes in retinal vessel caliber that are associated with ocular and systemic vascular diseases in adulthood [24]. A strong and independent association between adiposity and blood pressure was present during early childhood. These data have important public health implications because elevated blood pressure at a young age may be associated with increased cardiovascular risk in later life [25]. CO could induce some risk factors for cardiovascular disease including serum lipid abnormalities, hypertension, and atherosclerosis [26]. In our study population hypertension rate was significantly higher in obese group than control group.

The central obesity, as well as its combination with overweight or general obesity is more frequent in boys than in girls. Higher IOP was associated with the nonocular parameters of female sex, higher body mass index, younger age, maternal myopia and with the ocular parameters of longer axial and smaller corneal horizontal diameter [27]. Variations in the onset and peak progression of myopia may be associated with height spurts [28]. We have not found a significant difference in terms of refractive errors, biometric measurements or gender among subgroups.

In conclusion; our findings suggest that decreased CCT levels may be related to presence of IR in obese children. CCT is important for diagnostic and therapeutic purposes such as assessment before refractive surgery, monitoring corneal changes after extended contact lens wear, and determining the reliability of IOP measurements. In addition, hypertensive retinopathy can accompany hyperlipidemia in obese children. The role of IR, lipid and pubertal status should be further investigated with more subjects to compare the ophthalmic changes of obese population with non-obese ones.

\section{Conflict of interest}

No potential conflict of interest relevant to this article was reported.

\section{References}

1. Zagotta I, Dimova EY, Debatin KM et al. (2015) Obesity and inflammation: reduced cytokine expression due to resveratrol in a human in vitro model of inflamed adipose tissue. Front Pharmacol $14: 79$.

2. Cheung N, Wong TY (2007) Obesity and eye diseases. Surv Ophthalmol 52: 180-195 [Crossref]

3. Mladenova S, Andreenko E (2015) Prevalence of underweight, overweight, general and central obesity among 8-15-years old Bulgarian children and adolescents (Smolyan region, 2012-2014). Nutr Hosp 31: 2419-2427.

4. Pires A, Martins P, Pereira AM et al. (2015) Insulin Resistance, Dyslipidemia and Cardiovascular Changes in a Group of Obese Children. Arq Bras Cardiol 104: 266-273.

5. Albuquerque LL, Gaete MI, Figueiroa JN, Alves JG (2013) The correlation between body mass index and intraocular pressure in children. Arq Bras Oftalmol 76: 10-12. [Crossref]

6. Loureiro C, Godoy A, Martínez A, et al. (2015) Metabolic syndrome and its components are strongly associated with an inflammatory state and insulin resistance in the pediatric population. Nutr Hosp 31: 1513-1518.

7. Jiménez MV, Estepa RM, Camacho RM et al. (2007) Endothelial dysfunction is related to insulin resistance and inflammatory biomarker levels in obese prepubertal children. Eur J Endocrinol 156: 497-4502.

8. Winder AF, Dodson PM, Galton DJ (1980) Ophthalmological complications of the hypertriglyceridaemias. Trans Ophthalmol Soc U K 100: 119-122. [Crossref]

9. Zhai L, Liu J, Zhao J, Liu J, Bai Y, et al. (2015) Association of Obesity with Onset of Puberty and Sex Hormones in Chinese Girls: A 4-Year Longitudinal Study. PLoS One 10: e0134656. [Crossref]

10. Alves M1, Reinach PS, Paula JS, Vellasco e Cruz AA, Bachette L, et al. (2014) Comparison of diagnostic tests in distinct well-defined conditions related to dry eye disease. PLoS One 9: e97921. [Crossref]

11. Ozturk A, Mazicioglu MM, Hatipoglu N, Budak N, Keskin G, et al. (2008) Reference body mass index curves for Turkish children 6 to 18 years of age. J Pediatr Endocrinol Metab 21: 827-836. [Crossref] 
12. Vasquez F, Salazar G, Díaz E, Lera L, Anziani A, et al. (2016) Comparison of body fat calculations by sex and puberty status in obese schoolchildren using two and four compartment body composition models. Nutr Hosp 33: 575. [Crossref]

13. Özer S, Yılmaz R, Özlem Kazanci N, Sönmezgöz E, Karaaslan E, et al. (2014) Higher hdl levels are a preventive factor for metabolic syndrome in obese Turkish children. Nutr Hosp 31: 307-312. [Crossref]

14. Keskin M, Kurtoglu S, Kendirci M, Atabek ME, Yazici C (2005) Homeostasis mode assessment is more reliable than the fasting glucose/insulin ratio and quantitative insulin sensitivity check index for assessing insulin resistance among obese children and adolescents. Pediatrics 115: e500-e503.

15. Stąpor N, Beń-Skowronek I (2015) [Insulin resistance in children]. Pediatr Endocrinol Diabetes Metab 20: 107-115. [Crossref]

16. Magrone T, Jirillo E (2015) Childhood obesity: immune response and nutritional approaches. Front Immunol 6: 76. [Crossref]

17. Kurniawan ED, Cheung CY, Tay WT, Mitchell P, Saw SM, et al. (2014) The relationship between changes in body mass index and retinal vascular caliber in children. J Pediatr 165: 1166-1171. [Crossref]

18. Mori K, Ando F, Nomura H, Sato Y, Shimokata H (2000) Relationship between intraocular pressure and obesity in Japan. Int J Epidemiol 29: 661-666. [Crossref]

19. Lee JS, Choi YR, Lee JE et al. (2002) Relationship between intraocular pressure and systemic health parameters in the Korean population. Korean J Ophthalmol 16: 13-19.

20. Akinci A, Cetinkaya E, Aycan Z, Oner O (2007) Relationship between intraocular pressure and obesity in children. J Glaucoma 16: 627-630. [Crossref]
21. Koçak N, Arslan N, Karti O, Tokgoz Y, Ozturk T, et al. (2015) Evaluation of the intraocular pressure in obese adolescents. Minerva Pediatr 67: 413-418. [Crossref]

22. de Haseth K, Cheung N, Saw SM, Islam FM, Mitchell P, et al. (2007) Influence of intraocular pressure on retinal vascular caliber measurements in children. $\mathrm{Am} \mathrm{J}$ Ophthalmol 143: 1040-1042. [Crossref]

23. Xiao W, Gong W, Chen Q, Ding X, Chang B, et al. (2015) Association between body composition and retinal vascular caliber in children and adolescents. Invest Ophthalmol Vis Sci 56: 705-710. [Crossref]

24. Cheung N, Saw SM, Liew G et al. (2012) Childhood Vascular Risk Factors and Retinal Vessel Caliber. Asia Pac J Ophthalmol (Phila) 1: 193-197.

25. Gopinath B, Baur LA, Garnett S, Pfund N, Burlutsky G, et al. (2011) Body mass index and waist circumference are associated with blood pressure in preschool-aged children. Ann Epidemiol 21: 351-357. [Crossref]

26. Bijari B, Taheri F, Chahkandi T, Kazemi T, Namakin K, et al. (2015) The relationship between serum lipids and obesity among elementary school in Birjand: A case control study. J Res Health Sci 15: 83-87. [Crossref]

27. Jiang WJ, Wu JF, Hu YY, Wu H, Sun W, et al. (2014) Intraocular pressure and associated factors in children: the Shandong children eye study. Invest Ophthalmol Vis Sci 55: 4128-4134. [Crossref]

28. Yip VC, Pan CW, Lin XY, Lee YS, Gazzard G, et al. (2012) The relationship between growth spurts and myopia in Singapore children. Invest Ophthalmol Vis Sci 53: 79617966. [Crossref]

Copyright: $\odot 2017$ Kurtul BE. This is an open-access article distributed under the terms of the Creative Commons Attribution License, which permits unrestricted use, distribution, and reproduction in any medium, provided the original author and source are credited. 